\title{
Pepsinogen I and II expressions in situ and their correlations with serum pesignogen levels in gastric cancer and its precancerous disease
}

Ping Li, Caiyun He, Liping Sun, Nannan Dong and Yuan Yuan ${ }^{*}$

\begin{abstract}
Background: Serum pepsinogen (PG) I/II ratio has been widely used as "serological biopsy" for the screening of gastric cancer (GC) and atrophic gastritis (GA). However, study concerning in situ expression of PGs is currently insufficient, particularly for their relationship with serum PGs levels. This study was designed to investigate in situ expression of PGI and PGII in subjects with normal mucosa (NOR), superficial gastritis (GS), GA and GC, and to evaluate the correlations between PGs expressions in situ and in serum.

Methods: 185 subjects were enrolled for the study, including 30 NOR, 70 GS, 54 GA and 31 GC. PGI and PGII expressions in situ and in serum were detected by immunohistochemistry and enzyme-linked immunosorbent assay (ELISA) respectively. H. pylori immunoglobulin (lg) $\mathrm{G}$ was also determined by ELISA.

Results: In situ expressions of PGI, PGIl and PGI/II ratio consistently decreased in sequence of NOR/GS- > GA- > GC. The expressions of $P G I, P G I l$ and $P G I / I$ ratio in situ were statistically higher in youngers than in olders $(P<0.05)$. In the NOR subjects, $\mathrm{PGl}$ staining was statistically higher in males than that in females $(p=0.02)$. For the correlations between in situ and serum expressions of PGl, PGII and PGI/II ratio, a borderline correlation in the total study sample $(r=0.131, P=0.076)$ and a statistical correlation in $G A$ cases $(r=0.307, P=0.027)$ were observed for the $\mathrm{PGI} / \mathrm{Il}$ ratio. The $\mathrm{PGl}$ expression correlated well with that of $\mathrm{PGIl}$ in situ and in serum.

Conclusions: The in situ levels of PGI, PGII and PGI/II ratio sharply decreased in the GA and GC cases. The youngers exhibited higher levels of $P G \mid, P G I I$ and $P G I / I I$ ratios than the olders. The in situ PGI/II ratio rather than PGI and PGII alone showed certain correlation with that in serum, and the PGl expression correlated well with PGIl expression. Further studies with large-scale samples are still required to validate our findings.
\end{abstract}

Keywords: Pepsinogen, Gastric disease, Correlation

\section{Background}

Human gastric mucosa contains two abundant and distinguishable aspartic proteinases, namely pepsinogen I (PGI or PGA) and pepsinogen II (PGII or PGC) [1]. The majority of PGs are present in gastric mucosa and a small part of those may be released into blood [2]. Typically, PGs are present as zymogens in gastric mucosa and can be converted into active proteolytic forms under certain acidic condition in stomach lumen. The activated

\footnotetext{
* Correspondence: yyuan@mail.cmu.edu.cn

Tumor Etiology and Screening Department of Cancer Institute and General Surgery, Liaoning Provincial Education Department, The First Affiliated Hospital of China Medical University, Key Laboratory of Cancer Etiology and Prevention(China Medical University), 155\# North Nanjing Street, Heping District, Shenyang City 110001, Liaoning Province, China
}

pepsins are extremely important for the digestive process in stomach [1].

There are overwhelming epidemiological evidences supporting that serum level of PGI and/or PGI/II ratio correlates well with morphologic and functional changes of gastric mucosa [3-7]. Accordingly, they have been widely used as 'serological biopsy' for the screening of gastric cancer (GC) and its precancerous lesions [3-7]. In spite of the wide use of serum PGs in clinical practice, study concerning in situ expressions of PGs, particularly in the stepwise progression from normal mucosa (NOR), superficial gastritis (GS), atrophic gastritis (GA) to carcinoma, is currently insufficient. The questions whether the PGs expression changes in situ are synchronistic with

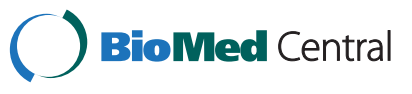


those in serum and which factors affect the in situ expression of PGs are still not resolved based on previous studies. These may, to some extent, puzzle the clinical work on how to appropriately interpret the variations of serum PGs expression in different status of gastric diseases.

The present study was conducted to investigate in situ expressions of PGI, PGII and PGI/II ratio in the sequence of NOR->GS->GA->GC. The possible influences of sex, age and $H$. pylori infection on PGs expressions in situ were also explored. Moreover, the correlations between in situ and serum expression of PGs and between PGI and PGII expression in situ and in serum were evaluated.

\section{Methods}

\section{Patients}

A total of 185 subjects (male 110 and female 75) were enrolled in this study, including NOR $(\mathrm{n}=30)$, GS $(n=70)$, GA $(n=54)$, and GC $(n=31)$. All the subjects were retrospectively enrolled from a health check program for gastric cancer screening in Zhuanghe county of Liaoning province, China between 1998 and 2010. The diagnosis of gastric disease was established by gastroscopic examination and confirmed by histopathology. Histopathological findings were assessed according to the Consensus on Chronic Gastritis formulated at the National Symposium in combination with the updated Sydney System and the World Health Organization (WHO) criteria [8-10]. The NOR individuals were confirmed to have relative normal gastric mucosa without evidence of H. pylori infection or gastrointestinal symptom. The GS subjects have only slight or moderate superficial gastritis without atrophic or intestinal metaplasia lesions. The GA cases have atrophic gastritis with or without intestinal metaplasia. Information of sex, age was retrospectively extracted from registered documents.

This cross-sectional study was approved by the Human Ethics Review Committee of China Medical University. Written informed consents were obtained from the participants.

\section{Immunohistochemistry staining of PGI and PGII}

For the retrieval of antigens, detection was performed in $5 \mu \mathrm{m}$-thick sections from sequentially sliced samples of paraffin-embedded specimens. Dewaxing sections were heated in citrate buffer $(\mathrm{pH}$ 6.0) using a microwave for $10 \mathrm{~min}$. Overnight incubation at $4^{\circ} \mathrm{C}$ was carried out for the binding of primary antibodies (PGI, anti-pepsinogen A antibody, trade name: 2 F5, 1:600 dilution; PGII, antipepsinogen $\mathrm{C}$ antibody, trade name: 2D5, 1:400 dilution; both antibodies were donated by Japan Clinical Inspection Institute) [11,12]. Afterwards, SP-two step immunostaining was performed according to the instructions of the kit (Kit-9801D2 from Maixin Company in Fujian, China). For all stainings, positive controls were carried out, and staining was accepted only if controls showed evaluable results.

\section{Assessment of immunohistochemical staining}

Immunohistochemical results were judged by IRS (immunoreactive score), which was determined by two independent observers. The IRS was calculated using two indexes of staining intensity (SI) and the percentage of positive cells (PP). The SI in cytoplasm was graded as: $0=$ no, $1=$ weak, $2=$ moderate, $3=$ strong staining. The PP was categorized as: $0=$ no stained cells, $1=$ stained cells $<25 \%, 2=$ stained cells $25 \sim 50 \%, 3=$ stained cells $51 \% \sim 75 \% ; 4=$ stained cells $>75 \%$. For each sample an IRS was calculated as SI $\times$ PP with a possible maximum score of 12 . The assessment result was defined as either negative $(0)$, weakly positive $(1 \sim 3)$, positive $(4 \sim 7)$ or strongly positive $(8 \sim 12)$.

In the present study, PGI staining was located in gastric corpus glands while PGII staining was located in both gastric corpus and antral mucosa. Therefore, PGI IRS was only assessed in the gastric corpus mucosa, and PGII IRS was assessed in both corpus and antral mucosa for each participant. For PGI staining, we evaluated the stained status of all the chief cells of gastric corpus glands for NOR and GS subjects, the remaining chief cells of subsistent corpus glands for GA subjects, and cells of the cancerous lesions for GC subjects. For PGII staining, we evaluated the staining status of all the gastric corpus and antrum glands for NOR and GS subjects, the remaining gastric corpus and antral glands for GA subjects, and cells of the cancerous lesion for GC subjects.

\section{Test for H. Pylori serology}

The detailed method of examination of $H$. pylori serology has been described in our previous study [13]. In brief, about five $\mathrm{ml}$ of fasting venous blood was collected from each participant. The serum sample was obtained after centrifugation at $3000 \times \mathrm{g}$ for 10 minutes. Serum Immunoglobin (Ig) $\mathrm{G}$ antibodies of $H$. pylori were detected by enzyme-linked immunosorbent assay (ELISA) kit (Biohit Co., Ltd., Helsinki, Finland) according to the manufacturer's instructions. A reading of $H$. pylori-IgG higher than 34 EIU (enzyme immune-units) was regarded as $H$. pylori seropositive.

\section{Test for serum PGI and PGII expression}

The detailed method of examination of serum pepsinogens has been described in our previous study [14]. Approximately $5 \mathrm{ml}$ fasting blood was collected from each participant. The blood was centrifuged at $3000 \times \mathrm{g}$ for 10 minutes and the serum was stored immediately at $-20^{\circ} \mathrm{C}$ until used. Serum PGI (sPGI) and PGII (sPGII) concentrations (microg/L) were detected by ELISA kit (Biohit Co., Ltd., 
Finland) according to the manufacturer's instructions. Five percent of all samples were assayed in duplicate.

\section{Statistical analysis}

All statistical analysis was performed using the SPSS (13.0) program (SPSS, Chicago, USA). The distributions of discrete variables were represented as frequencies and percentages. The averages of continuous variables were represented as median (25\%, $75 \%)$. The positive rates of PGI and PGII staining in different gastric diseases were compared by Pearson's Chi-square test or Fisher's exact test. The correlation coefficient between two variables was measured by partial correlation controlling for sex and age. The IRS of in situ expression of PGI, PGII and PGI/II ratio among multiple groups were compared by the Kruskal-Wallis test; if statistical significance $(\mathrm{P}<0.05)$ was indicated, the difference between two groups was further tested by the Mann-Whitney $U$-test. A two-tailed $P$ value less than 0.05 was considered as statistically significant.

\section{Result}

Dynamic in situ expression of PGs in different gastric tissues Both PGI and PGII staining were located in the cytoplasm and cell membrane of gastric epithelial cells but in different part of stomach. Staining for PGI was positive in corpus mucosa but negative in all antral mucosa regardless of the status of gastric mucosa (Figures 1 and 2). PGII staining was present in both corpus and antral mucosa (Figures 3 and 4). None of the intestinal metaplasia cells exhibited the PGI or PGII staining. As demonstrated in Table 1, along the sequence of NOR/GS->GA-> GC, the positive rates and strongly-positive rates of both PGI and PGII expression showed significantly decreased tendencies.

To further investigate the relative expression of PGI to PGII in situ, the ratio of PGI IRS to PGII IRS was calculated, namely in situ PGI/II ratio. We found that in situ PGI/II ratios also showed a decreased tendency in the sequence of NOR/GS- > GA- > GC, showed corresponding average level of 1.0/1.0, 0.8 and 0 (All the IRS of PGI and PGII staining in GC tissue were zero). In situ PGI/II ratios in GA were statistically lower than those in GS $(P=0.005)$.

\section{In situ expression of PGs in different status of sex, age and $H$. pylori infection}

The differences of the IRS of PGs staining between females and males, between youngers (age $<50$ years) and olders (age $\geq 50$ years), and between $H$. pylori seropositive and seronegative subpopulations were evaluated in the total study sample and in the NOR, GS and GA subgroups (Table 2). Of the total study sample, in situ levels of PGI, PGII and PGI/II ratio were observed to be statistically

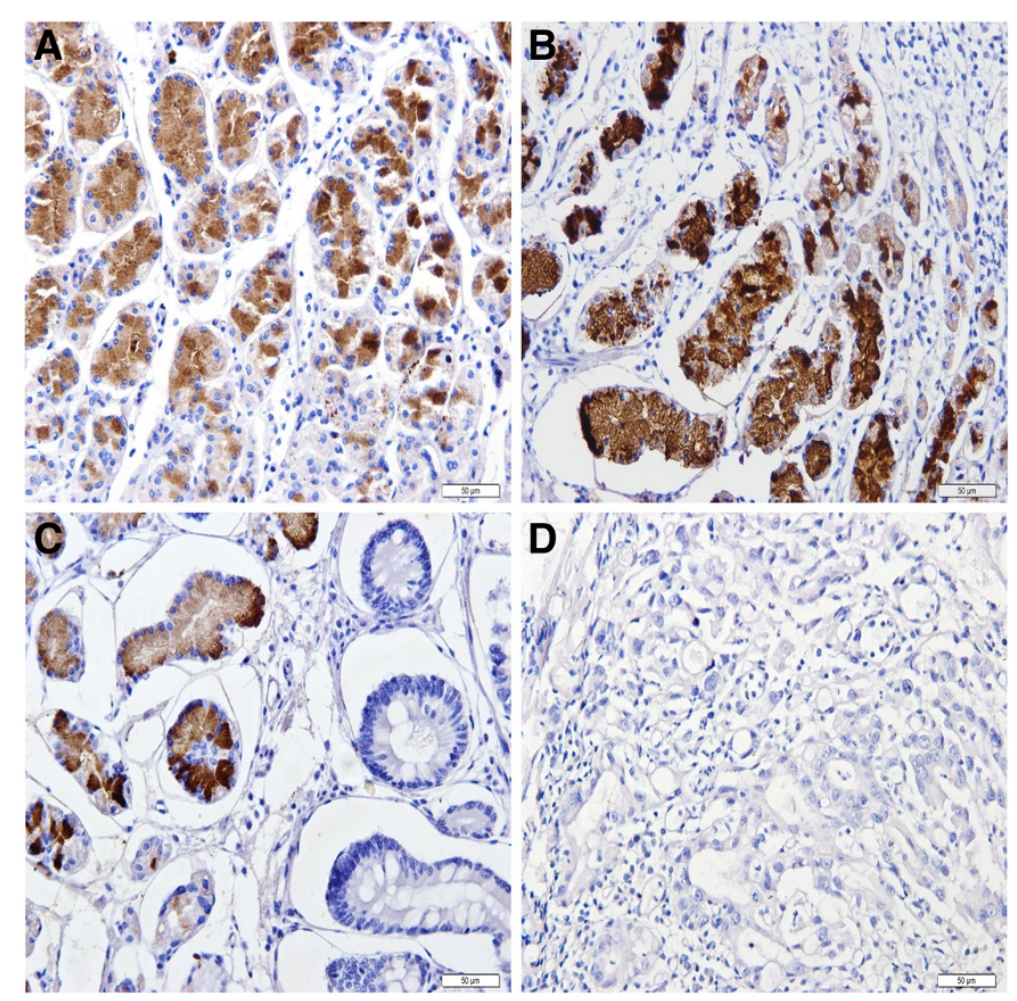

Figure 1 Expression of PGI in corpus glands in different gastric tissues (immunohistochemical staining $\times 200$ ). (A) NOR mucosa; (B) GS mucosa; (C) GA mucosa; (D) GC mucosa. 


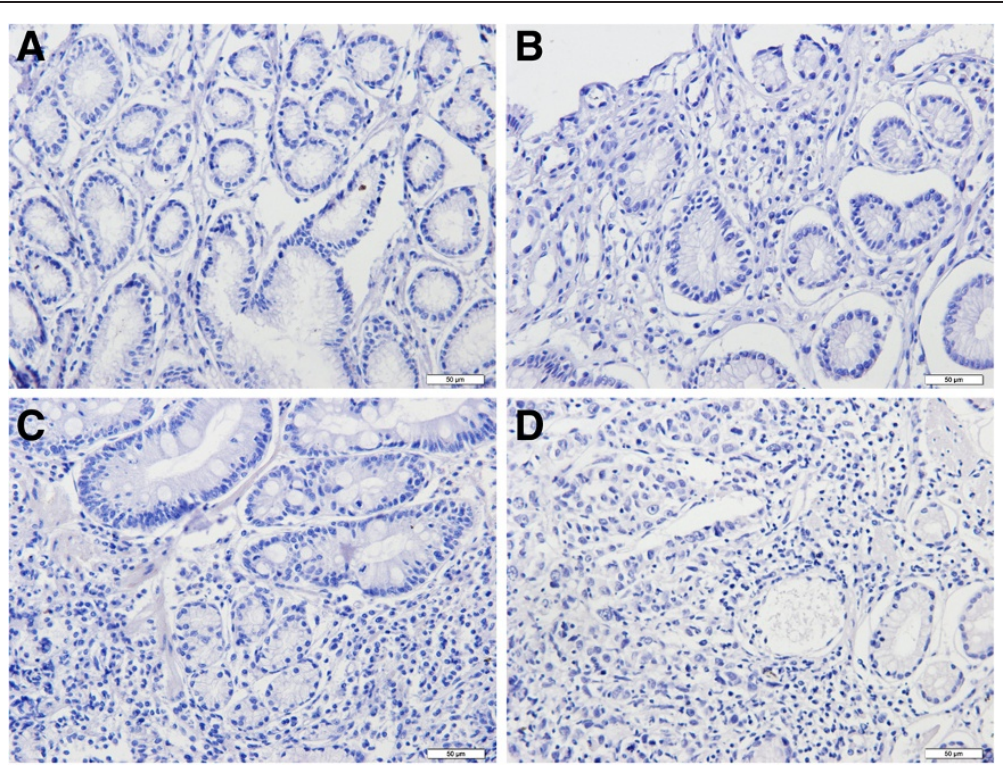

Figure 2 Negative expression of PGI in all antral glands in different gastric tissues (immunohistochemical staining $\times 200$ ).

(A) NOR mucosa; (B) GS mucosa; (C) GA mucosa; (D) GC mucosa.
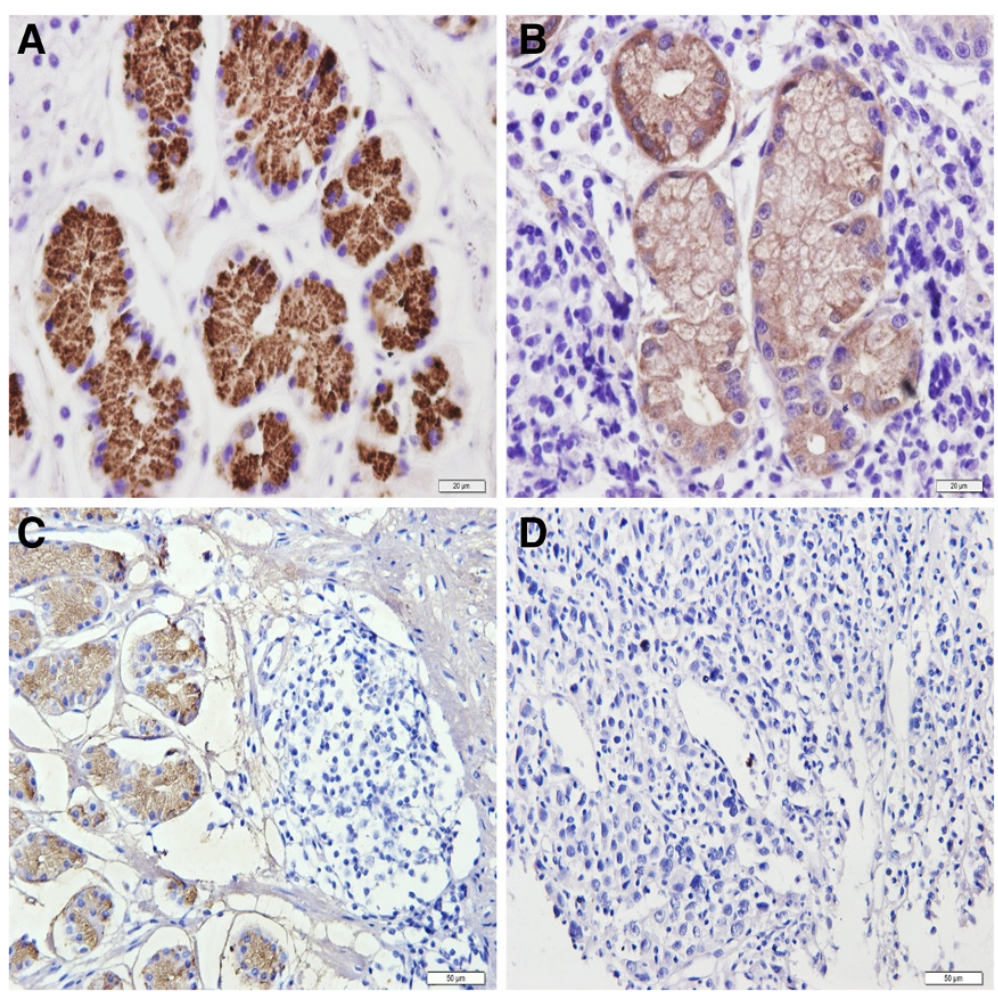

Figure 3 Expression of PGII in corpus glands in different gastric tissues (immunohistochemical staining $\times 200$ ). (A) NOR mucosa; (B) GS mucosa; (C) GA mucosa; (D) GC mucosa. 


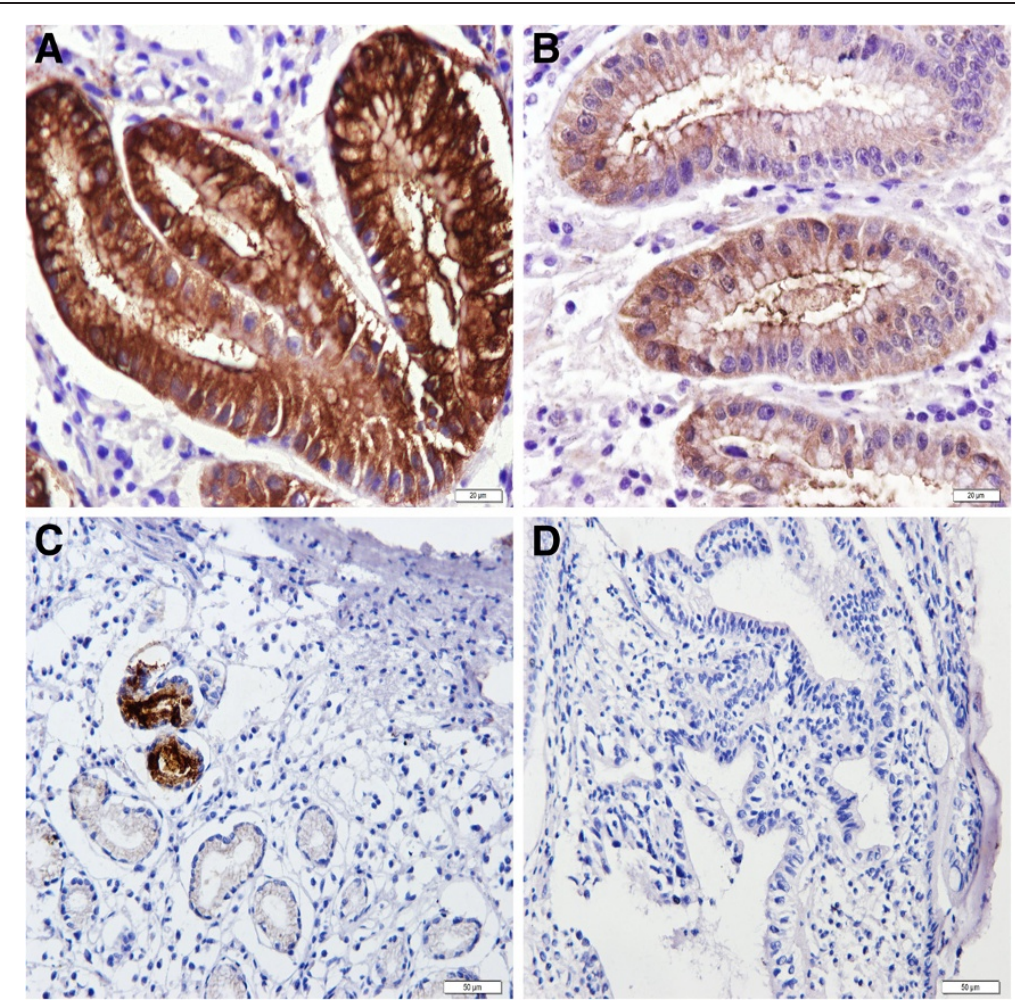

Figure 4 Expression of PGII in antral glands in different gastric tissues. (A) NOR mucosa (immunohistochemical staining $\times 400$ ); (B) GS mucosa (immunohistochemical staining $\times 400$ ); (C) GA mucosa (immunohistochemical staining $\times 200$ ); (D) GC mucosa (immunohistochemical staining $\times 200$ ).

higher in the youngers than in the olders. There were no statistical differences between the youngers and the olders in the subgroups of NOR, GS or GA. In addition, in situ PGI expression was found to be statistically higher in males than that in females in the NOR subgroup.
Correlations between PGs expression in situ and in serum The expression levels of PGI, PGII and PGI/II ratio in situ and in serum were summarized in Table 3. We explored the correlations between in situ and serum levels of PGI, PGII and PGI/II ratio (Table 4). A borderline

Table 1 In situ expression of PGs in different gastric mucosa

\begin{tabular}{|c|c|c|c|c|c|c|c|c|c|c|c|c|c|}
\hline & \multirow[t]{2}{*}{$\mathrm{N}$} & \multirow{2}{*}{$\begin{array}{l}\text { Positive } \\
\text { rate }\end{array}$} & \multicolumn{3}{|c|}{$P$ value } & \multirow{2}{*}{$\begin{array}{l}\text { Strongly-positive } \\
\text { rate }\end{array}$} & \multicolumn{3}{|c|}{$P$ value } & \multirow{2}{*}{$\begin{array}{c}\text { in situ } \\
\text { PGI/II ratio }{ }^{a}\end{array}$} & \multicolumn{3}{|c|}{$P$ value } \\
\hline & & & vs. NOR & vs. GS & vs. GA & & vs. NOR & vs. GS & vs. GA & & vs. NOR & vs. GS & vs. GA \\
\hline \multicolumn{14}{|c|}{ In situ PGI expression } \\
\hline NOR & 30 & $100.00 \%$ & & & & $50.00 \%$ & & & & $1.0(0.7,1.1)$ & & & \\
\hline GS & 70 & $100.00 \%$ & / & & & $32.90 \%$ & $0.021^{b}$ & & & $1.0(0.7,1.4)$ & $0.292^{d}$ & & \\
\hline GA & 54 & $83.30 \%$ & $0.023^{c}$ & $<0.001^{c}$ & & $3.70 \%$ & $<0.001^{b}$ & $<0.001^{b}$ & & $0.8(0.4,1.1)$ & $0.086^{d}$ & $0.005^{d}$ & \\
\hline GC & 31 & $0.00 \%$ & $<0.001^{b}$ & $<0.001^{b}$ & $<0.001^{b}$ & $0.00 \%$ & $<0.001^{b}$ & $<0.001^{\mathrm{b}}$ & $<0.001^{\mathrm{b}}$ & $0.0(0.0,0.0)$ & $<0.001^{d}$ & $<0.001^{d}$ & $<0.001^{d}$ \\
\hline \multicolumn{14}{|c|}{ In situ PGIl expression } \\
\hline NOR & 30 & $100.00 \%$ & & & & $63.30 \%$ & & & & / & & & \\
\hline GS & 70 & $100.00 \%$ & / & & & $31.40 \%$ & $0.015^{b}$ & & & / & & & \\
\hline GA & 54 & $92.60 \%$ & $0.291^{c}$ & $0.034^{c}$ & & $1.90 \%$ & $<0.001^{b}$ & $<0.001^{b}$ & & / & & & \\
\hline GC & 31 & $0.00 \%$ & $<0.001^{b}$ & $<0.001^{b}$ & $<0.001^{\mathrm{b}}$ & $0.00 \%$ & $<0.001^{b}$ & $<0.001^{b}$ & $<0.001^{b}$ & / & & & \\
\hline
\end{tabular}

${ }^{a}$, the ratios of PGI IRS to PGII IRS were represented as median $(25 \%, 75 \%) ;{ }^{b}$, the positive rates and strongly-positive rates of PGI and PGII staining in different gastric diseases were compared by Pearson's Chi-square test; ${ }^{c}$, the positive rates of PGI and PGIl expression in different gastric diseases were determined by Fisher's exact test; ${ }^{d}$, the in situ PGI/II ratios among multiple gastric diseases were first tested by Kruskal-Wallis test. If the result was indicated as statistically significant, the Mann-Whitney test was performed to further test the different between two groups. Analyses results with $\mathrm{P}<0.05$ were highlighted in bold characters. 
Table 2 In situ expression of PGs in different sex, age and H. pylori status

\begin{tabular}{|c|c|c|c|c|c|c|c|c|}
\hline & $\begin{array}{c}\text { Total } \\
\text { IRS score }\end{array}$ & & $\begin{array}{c}\text { NOR } \\
\text { IRS score }\end{array}$ & & $\begin{array}{c}\text { GS } \\
\text { IRS score }{ }^{a}\end{array}$ & & $\begin{array}{c}\text { GA } \\
\text { IRS score }{ }^{a}\end{array}$ & \\
\hline \multicolumn{9}{|l|}{ In situ PGI staining } \\
\hline Sex & & 0.265 & & 0.002 & & 0.599 & & 0.964 \\
\hline Female & $4.0(2.0,7.0)$ & & $5.0(4.0,7.5)$ & & $6.0(4.0,9.0)$ & & $2.0(1.0,3.3)$ & \\
\hline Male & $3.0(0.0,7.0)$ & & $9.0(7.0,10.5)$ & & $6.0(2.5,8.5)$ & & $2.0(1.0,3.0)$ & \\
\hline Age(years) & & 0.003 & & 0.681 & & 0.183 & & 0.563 \\
\hline$<50$ & $4.0(2.0,9.0)$ & & $7.5(5.5,9.3)$ & & $7.0(3.0,10.0)$ & & $2.0(1.0,4.0)$ & \\
\hline$\geq 50$ & $3.0(0.0,6.0)$ & & $7.5(5.0,10.8)$ & & $5.0(3.0,7.0)$ & & $2.0(1.0,3.0)$ & \\
\hline H. pylori lgG & & 0.359 & & / & & 0.515 & & 0.659 \\
\hline EIU $<34$ & $3.0(1.0,6.0)$ & & $7.5(5.0,10.0)$ & & $5.0(3.0,9.3)$ & & $2.0(1.0,3.0)$ & \\
\hline$E I U \geq 34$ & $2.0(0.0,6.0)$ & & / & & $6.0(4.0,8.8)$ & & $2.0(1.0,3.5)$ & \\
\hline \multicolumn{9}{|l|}{ In situ PGII staining } \\
\hline Sex & & 0.073 & & 0.363 & & 0.245 & & 0.643 \\
\hline Female & $3.0(1.0,7.0)$ & & $7.0(4.5,11.0)$ & & $6.0(4.0,9.0)$ & & $3.0(1.0,5.0)$ & \\
\hline Male & $5.0(2.0,7.0)$ & & $9.0(7.5,10.0)$ & & $5.0(3.0,9.0)$ & & $2.0(1.3,4.0)$ & \\
\hline Age(years) & & 0.003 & & 0.198 & & 0.260 & & 0.173 \\
\hline$<50$ & $5.0(2.0,9.0)$ & & $7.5(4.0,9.0)$ & & $6.5(3.3,9.8)$ & & $3.0(2.0,5.8)$ & \\
\hline$\geq 50$ & $3.0(0.0,6.3)$ & & $9.5(6.0,11.0)$ & & $5.0(2.0,8.0)$ & & $2.0(1.0,4.0)$ & \\
\hline H. pylori lgG & & 0.942 & & / & & 0.344 & & 0.069 \\
\hline EIU $<34$ & $3.0(1.0,6.0)$ & & $8.5(5.8,10.3)$ & & $6.0(2.0,9.0)$ & & $2.0(1.0,3.0)$ & \\
\hline$E I U \geq 34$ & $3.0(0.0,6.0)$ & & / & & $5.5(4.0,9.8)$ & & $3.0(2.0,5.5)$ & \\
\hline \multicolumn{9}{|l|}{ In situ PGI/PGII staining } \\
\hline Sex & & 0.453 & & 0.123 & & 1.000 & & 0.650 \\
\hline Female & $0.8(0.4,1.3)$ & & $0.8(0.5,1.0)$ & & $1.0(0.7,1.5)$ & & $0.6(0.2,1.2)$ & \\
\hline Male & $0.8(0.0,1.1)$ & & $1.0(0.8,1.2)$ & & $1.0(0.7,1.5)$ & & $0.8(0.4,1.0)$ & \\
\hline Age(years) & & 0.011 & & 0.530 & & 0.864 & & 0.462 \\
\hline$<50$ & $1.0(0.6,1.3)$ & & $1.0(0.6,1.6)$ & & $1.0(0.7,1.4)$ & & $1.0(0.4,1.0)$ & \\
\hline$\geq 50$ & $0.7(0.0,1.0)$ & & $01.0(0.8,1.0)$ & & $1.0(0.7,1.5)$ & & $0.7(0.1,1.0)$ & \\
\hline H. pylori lgG & & 0.062 & & / & & 0.763 & & 0.599 \\
\hline$E I U<34$ & $0.9(0.3,1.4)$ & & $1.0(0.7,1.1)$ & & $1.0(0.7,1.5)$ & & $0.8(0.2,2.5)$ & \\
\hline$E I U \geq 34$ & $0.6(0.0,1.0)$ & & / & & $1.0(0.7,1.4)$ & & $0.7(0.4,1.0)$ & \\
\hline
\end{tabular}

a, IRS of PGI, PGII and PGI/II ratio were represented as median $(25 \%, 75 \%)$; ${ }^{\text {, }}$, in situ expression of PGI, PGII, PGI/II ratio between two groups were compared by Mann-Whitney test. Analyses results with $\mathrm{P}<0.05$ were highlighted in bold characters.

Table 3 Expression of PGI, PGII and PGI/II ratio in situ and in serum

\begin{tabular}{cccccccc}
\hline Gastric mucosa & N & $\begin{array}{c}\text { In situ } \\
\text { PGI (IRS) }\end{array}$ & $\begin{array}{c}\text { In situ } \\
\text { PGII (IRS) }\end{array}$ & $\begin{array}{c}\text { In situ } \\
\text { PGI/II ratio }\end{array}$ & $\begin{array}{c}\text { Serum } \\
\text { PGI (microg/L) }\end{array}$ & $\begin{array}{c}\text { Serum } \\
\text { PGI (microg/L) }\end{array}$ & $\begin{array}{c}\text { Serum } \\
\text { PGI/II ratio }\end{array}$ \\
\hline NOR & 30 & $7.5(5.0,10.0)$ & $8.5(5.8,10.3)$ & $1.0(0.7,1.1)$ & $68.2(47.8,146.8)$ & $6.3(4.1,9.2)$ & $15.3(8.9,20.2)$ \\
GS & 70 & $6.0(3.0,9.00$ & $6.0(3.0,9.0)$ & $1.0(0.7,1.4)$ & $72.5(53.5,102.3)$ & $6.4(4.3,13.9)$ & $9.8(7.6,14.3)$ \\
GA & 54 & $2.0(1.0,3.0)$ & $2.5(1.0,4.3)$ & $0.8(0.4,1.1)$ & $87.4(56.3,127.1)$ & $10.7(6.6,15.6)$ & $8.6(4.8,12.4)$ \\
GC & 31 & $0.0(0.0,0.0)$ & $0.0(0.0,0.0)$ & $0.0(0.0,0.0)$ & $86.6(64.8,139.2)$ & $15.8(7.7,24.9)$ & $6.1(3.7,11.7)$ \\
\hline
\end{tabular}


Table 4 Correlation between PGs expression in situ and in serum

\begin{tabular}{|c|c|c|c|c|c|c|c|c|c|c|}
\hline & \multicolumn{2}{|c|}{$\begin{array}{c}\text { In situ PGI } \\
\text { and serum PGI }\end{array}$} & \multicolumn{2}{|c|}{$\begin{array}{c}\text { In situ PGII } \\
\text { and serum PGII }\end{array}$} & \multicolumn{2}{|c|}{$\begin{array}{c}\text { In situ PGI/II } \\
\text { and serum PGI/II }\end{array}$} & \multicolumn{2}{|c|}{$\begin{array}{c}\text { In situ PGI } \\
\text { and In situ PGII }\end{array}$} & \multicolumn{2}{|c|}{$\begin{array}{c}\text { Serum PGI } \\
\text { and Serum PGII }\end{array}$} \\
\hline & $\mathbf{R}$ & $P$ value & $\mathbf{R}$ & $P$ value & $\mathbf{R}$ & $P$ value & $\mathbf{R}$ & $P$ value & $\mathbf{R}$ & $P$ value \\
\hline Total & -0.017 & 0.815 & -0.138 & 0.063 & 0.131 & 0.076 & 0.737 & $<0.001$ & 0.687 & $<0.001$ \\
\hline NOR & 0.135 & 0.492 & 0.124 & 0.529 & 0.291 & 0.132 & 0.340 & 0.076 & 0.766 & $<0.001$ \\
\hline GS & 0.122 & 0.320 & 0.164 & 0.181 & -0.046 & 0.707 & 0.527 & $<0.001$ & 0.705 & $<0.001$ \\
\hline GA & -0.131 & 0.356 & -0.139 & 0.324 & 0.307 & 0.027 & 0.540 & $<0.001$ & 0.613 & $<0.001$ \\
\hline GC & / & / & 0.091 & 0.639 & / & / & / & / & 0.730 & $<0.001$ \\
\hline
\end{tabular}

Note: All the correlation coefficients were calculated by partial correlation controlling for the status of sex and age. Analyses results with $\mathrm{P}<0.05$ were highlighted in bold characters.

correlation in the total study sample $(\mathrm{r}=0.131, \mathrm{P}=0.076)$ and a statistical correlation in GA cases $(r=0.307$, $\mathrm{P}=0.027$ ) were observed for the correlation between in situ and serum levels of PGI/II ratio (Figure 5). However, we found no statistical correlation between in situ and serum expression of PGI or PGII in the total study sample or in the subgroups of different diseases (all $\mathrm{P}>0.05$ ) (Figure 6).

We further investigated the correlations between PGI and PGII (Table 4). Notably, the changes of PGI expression correlated well with the changes of PGII expression no matter in situ or in serum. For the correlation between in situ PGI expression and in situ PGII expression, there were statistically significant correlations in the total study sample (Figure 5) and in the subgroups of GS and GA and a borderline correlation in NOR subgroup. For the correlation between serum PGI expression and serum PGII expression, statistically significant correlations were found in the total study sample (Figure 5) and in all the subgroups of different stomach diseases.

\section{Discussion}

PGI and PGII are main progastricsins in the stomach, which closely reflects functional and morphological changes of gastric mucosa $[15,16]$. In the present study, we found that in situ levels of PGI, PGII and PGI/II ratio consistently decreased in sequence of NOR/GS- > GA- > GC, especially in GA and GC. The youngers exhibited higher levels of PGI, PGII and PGI/II ratio than the olders. Interestingly, we found statistical correlations between in situ and serum levels of PGI/II ratio in GA cases and between PGI and PGII no matter in situ or in serum. There was lack of statistical correlation between in situ and serum expressions of PGI or PGII alone in this study.

It is widely accepted that the carcinogenesis process of gastric cancer progresses stepwise from normal stomach, inflammation, precancerous conditions, and to carcinoma, as described by Correa's cascade [17]. In the sequence of NOR/GS- > GA-> GC, consistently decreasing tendencies of in situ levels of PGI, PGII and PGI/II ratio were observed in this study. Although both NOR and GS subjects showed an extremely high positive rate of $100 \%$ of in situ PGs expression, the strongly-positive rates in GS cases significantly declined. In mild gastritis, inflammation could stimulate the production of PGs by increasing gastrin secretion; while in severe gastritis, the intensive inflammation could reversely reduce the PGs production mainly owing to injured and reduced gastric glands [18]. When it comes to GA, the positive rates of PGs expression decreased sharply, probably because the decreasing number of glands and prolonged inflammation response in GA could impair normal gland function and synthesizing capability of PGs-producing cells. Further, the synthesis function would substantially lose in intestinal metaplasia cells or cancerous cells.

A proportion of severe and extensive chronic GA could evolve into severe dysplasia and even gastric carcinoma [19]. Thus, the early diagnosis of GA is crucial for slowing down the malignant progression process of gastric mucosa. However, in clinical practice there is still certain difficulty in the early recognition of atrophy and cancerous lesions among pathologists based on haematoxylin-eosin staining of gastric biopsy. In this study, we found that only partial normal cells of remaining gastric glands in GA cases exhibited weak or moderate staining of PGI and PGII, while no PGs staining was detected in the lesions with severe atrophy, intestinal metaplasia or carcinoma. Previously, Waalewijn RA et al. [20] reported that PGI mRNA level in gastric cancer tissue was relatively low. StemmerMann GN et al. [21] showed that only $4.5 \%$ of well-differentiated intestinal-type GC and none of diffuse-type GC was PGIpositive staining. Our previous study also demonstrated that the positive rates of PGII expression decreased gradually in sequence of benign lesions, precancerous lesions and gastric cancer [12]. These observations strongly suggested that the detection of in situ PGs expression may be important auxiliary biomarkers for the recognition of the location of atrophy and carcinoma.

Serum PGs have been widely used as biomarkers for GC or GA in clinical practice [3-7]. However, the question of whether the PGs expression changes in 

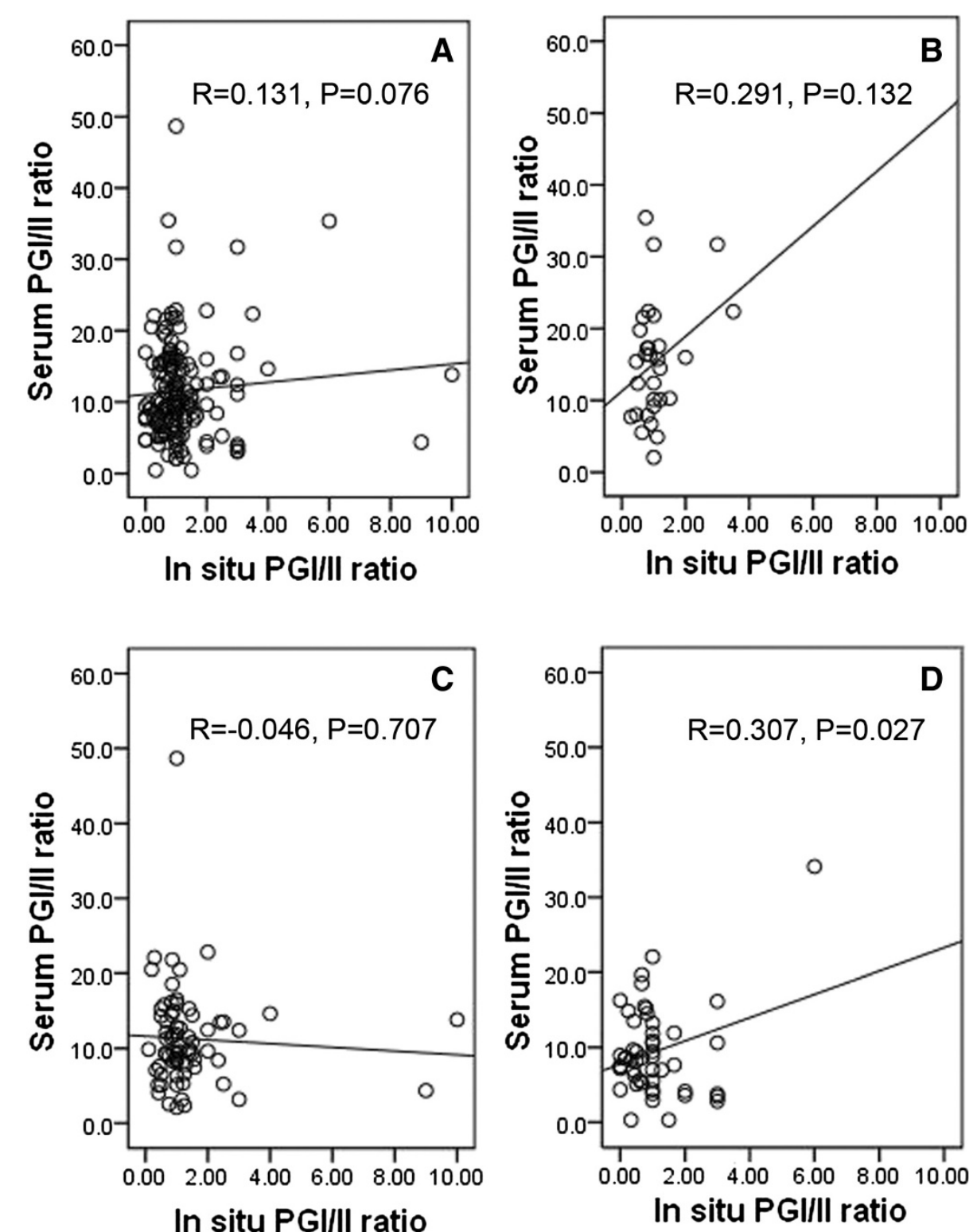

Figure 5 Scatter plots of correlations between in situ PGI/II ratio and serum PG/II ratio. (A) correlation between in situ PGI/II ratio and serum PGI/II ratio in total study sample; (B) correlation between in situ PGI/II ratio and serum PGI/II ratio in NOR subgroup; (C) correlation between in situ PGI/II ratio and serum PGI/II ratio in GS subgroup; (D) correlation between in situ PGI/II ratio and serum PGI/II ratio in GA subgroup.

situ are synchronistic with those in serum is still unclear. In the present study, we explored the correlations between in situ and serum expressions of PGs (including PGI, PGII and PGI/II ratio) and between PGI and PGII expressions (including in situ and in serum). However, there was lack of correlations between in situ and serum expressions of PGI or PGII in this study. One of the possible reasons for negative correlations between in situ and serum expression of PGI or PGII may be that the majority of PGs production are restricted to gastric mucosa, and only about $1 \%$ are released into blood, which may lead to nonsynchronous alterations between in situ and serum PGs expressions [1]. Another possible reason is that, apart from the influence of PGs production in stomach, the inflow of PGs from gastric epithelial cell to blood may be affected by other potential factors, such as different damage degrees of gastric epithelial cells, different vascular permeability, and different metabolic mechanisms between in situ and serum PGs [22]. Interestingly, we observed a borderline correlation in the total study sample and a statistical correlation in GA cases between in situ and serum levels of PGI/II ratio. This observation indicated that in the 

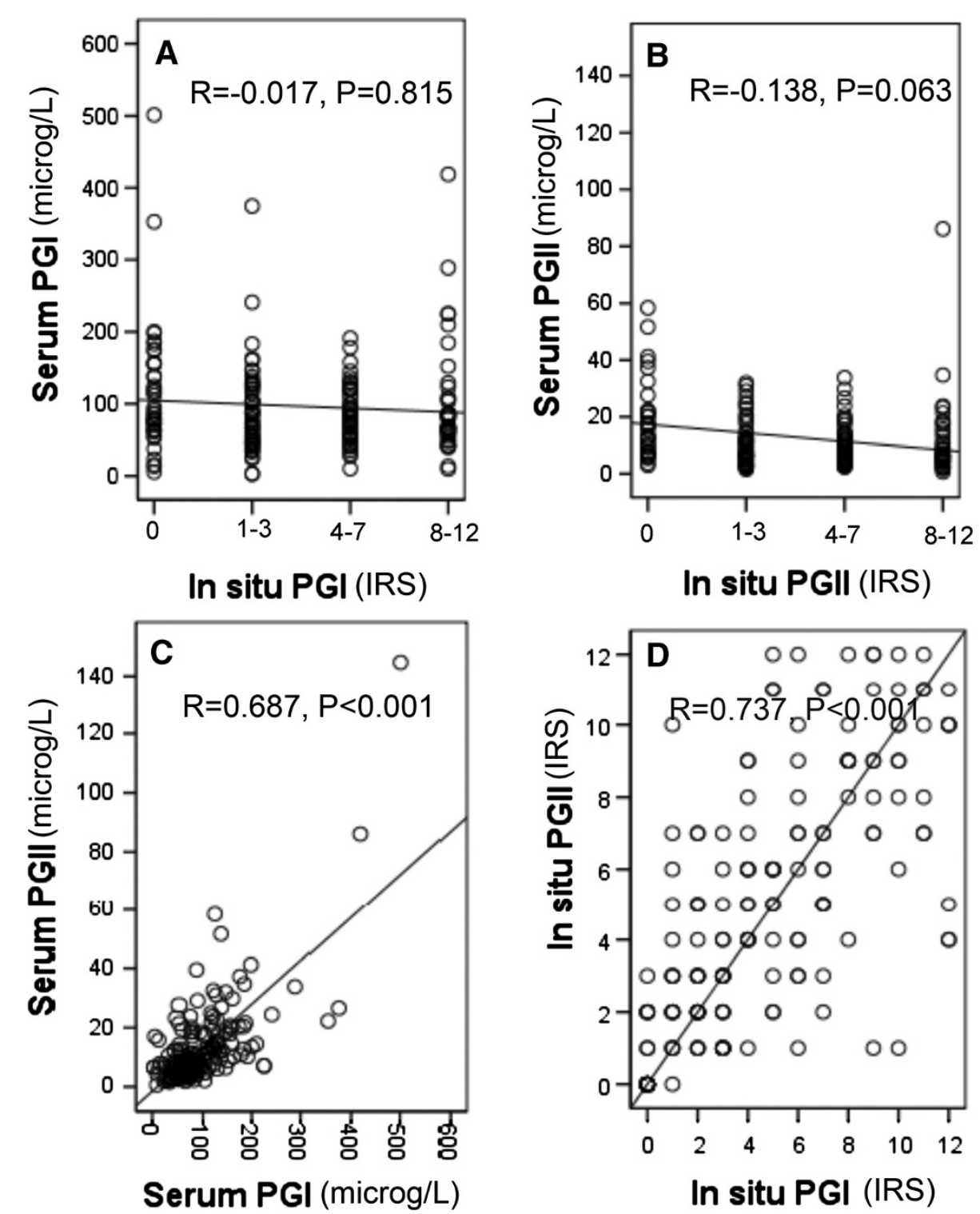

Figure 6 Scatter plots of correlations between pepsinogens. (A) correlation between in situ PGI (IRS scores were divided into four subgroup, i.e. $0,1-3,4-7,8-12$ ) and serum PGI in total study sample; (B) correlation between in situ PGII (IRS scores were divided into four subgroup, i.e. 0, 1-3, 4-7, 8-12) and serum PGIl in total study sample; (C) correlation between serum PGI and serum PGIl in total study sample; (D) correlation between in situ PGI (IRS score) and in situ PGII (IRS score) in total study sample.

subjects with precancerous diseases, the serum level of PGI/II ratio, rather than serum levels of PGI or PGII alone, may be a better index that reflects the decreasing tendencies of both PGI and PGII expression in situ. This may partially explain why serum level of PGI/II ratio showed a more close correlation with GC and GA but not serum PGI or PGII alone. In addition, we found that the PGI expression correlated well with PGII expression in situ and in serum, which indicated that PGI and PGII levels change simultaneously regardless of the status of gastric mucosa. In other words, synchronous changes of PGI and PGII expressions in situ or in serum may specifically reflect the damage of gastric mucosa. However, further studies with large-scale samples are still required to validate our findings.

We are aware that there are several limitations in this study. First, the study sample size of each disease group is relatively small, which limits our stratification analysis based on different histological classifications or severity degrees. Second, only a single method was used to detect the status of $H$. pylori infection in this study population; therefore, we only evaluated the potential influence of different status of H. pylori serology on the in situ PGs expression. Third, in this study we only investigated 
PGs expression in four sequentially-evolved groups of gastric mucosa, i.e. NOR, GS, GA and GC. A longtime follow-up study of PGs expression in situ as well as in serum in the same subjects whose stomach mucosa underwent sequential changes of NOR-> GS- > GA- > GC. Further study will be required to confirm our findings and to better guide the further use of PGs in future clinical practice.

\section{Conclusions}

In conclusion, the in situ levels of PGI, PGII and PGI/II ratio sharply decreased in the GA and GC cases. The younger people exhibited higher levels of PGI, PGII and PGI/II ratios than the older people. The in situ PGI/II ratio rather than PGI and PGII alone showed certain correlation with that in serum, and the PGI expression correlated well with PGII expression. Further studies with large-scale samples are still required to validate our findings.

\section{Abbreviations \\ GC: Gastric cancer; GS: Superficial gastritis; GA: Atrophic gastritis; NOR: Normal mucosa; PGI: Pepsinoen I; PGII: Pepsinogen II; ELISA: Enzyme-linked immunosorbent assay; IRS: Immunoreactive score; IgG: Immunoglobulin G.}

\section{Competing interests}

The authors declare that they have no competing interests.

\section{Authors' contributions}

PL performed the experiments and drafted the manuscript. CYH performed the statistical analysis. LPS, NND carried out the immunoassays. YY conceived of the study, and participated in its design and coordination. All authors read and approved the final manuscript.

\section{Acknowledgements}

This study is supported by grants from National Basic Research Program of China (973 Program Ref No.2010CB529304), the Foundation of the Key Laboratory in Liaoning Province (Ref No.LS2010167) and the grants of the Science Project of Liaoning Province (Ref [2008]621).

Received: 9 December 2012 Accepted: 12 August 2013

Published: 2 September 2013

\section{References}

1. Kageyama T: Pepsinogens, progastricsins, and prochymosins: structure, function, evolution, and development. Cell Mol Life Sci 2002, 59(2):288-306.

2. Rotter JI, Wong FL, Samloff IM, Varis K, Siurala M, Ihamaki T, Ellis A, McConnell RB: Evidence for a major dominance component in the variation of serum pepsinogen I levels. Am J Hum Genet 1982, 34(3):395-401.

3. Yoshihara M, Sumii K, Haruma K, Kiyohira K, Hattori N, Kitadai Y, Komoto K, Tanaka S, Kajiyama G: Correlation of ratio of serum pepsinogen I and II with prevalence of gastric cancer and adenoma in Japanese subjects. Am J Gastroenterol 1998, 93(7):1090-1096.

4. Dinis-Ribeiro M, da Costa-Pereira A, Lopes C, Barbosa J, Guilherme M, Moreira-Dias L, Lomba-Viana H, Silva R, Abreu N, Lomba-Viana R: Validity of serum pepsinogen $\mathrm{I} / \mathrm{I}$ ratio for the diagnosis of gastric epithelial dysplasia and intestinal metaplasia during the follow-up of patients at risk for intestinal-type gastric adenocarcinoma. Neoplasia New York, NY 2004, 6(5):449-456.

5. Abnet CC, Zheng W, Ye W, Kamangar F, Ji BT, Persson C, Yang G, Li HL, Rothman N, Shu XO, et al: Plasma pepsinogens, antibodies against helicobacter pylori, and risk of gastric cancer in the shanghai Women's health study cohort. Br J Cancer 2011, 104(9):1511-1516.
6. Haneda M, Kato M, Ishigaki S, Suzuki M, Takahashi M, Nakagawa M, Ono S, Mori Y, Mabe K, Nakagawa S, et al: The identification for high risk group of gastric cancer using serum pepsinogen after successful eradication of helicobacter pylori. J Gastroenterol Hepatol 2013, 28(1):78-83.

7. Kim N, Jung HC: The role of serum pepsinogen in the detection of gastric cancer. Gut and liver 2010, 4(3):307-319.

8. Lin SB, Yu ZL, Hu PJ, Wang CW, Xu GM, Xiao SD, Shi R, Liu WZ: Consensus on chronic gastritis formulated at the national symposium. Zhonghua Xiaohua Zazhi 2000, 20:199-201.

9. Dixon MF, Genta RM, Yardley JH, Correa P: Classification and grading of gastritis. The updated Sydney system. International workshop on the histopathology of Gastritis, Houston 1994. Am J Surg Pathol 1996, 20(10):1161-1181.

10. Hamilton SR, Aaltonen LA: Pathology and genetics of tumors of the digestive system. In World health organization classification of tumors. Edited by Kleihues P, Sobin LH. Lyon: IARC Press; 2000:37-50.

11. Konishi N, Matsumoto K, Hiasa Y, Kitahori Y, Hayashi I, Matsuda H: Tissue and serum pepsinogen I and II in gastric cancer identified using immunohistochemistry and rapid ELISA. J Clin Pathol 1995, 48(4):364-367.

12. Ning PF, Liu HJ, Yuan Y: Dynamic expression of pepsinogen $C$ in gastric cancer, precancerous lesions and helicobacter pylori associated gastric diseases. World J Gastroenterol 2005, 11(17):2545-2548.

13. Gong YH, Sun LP, Jin SG, Yuan Y: Comparative study of serology and histology based detection of helicobacter pylori infections: a large population-based study of 7,241 subjects from China. Eur J Clin Microbiol Infect Dis 2010, 29(7):907-911.

14. Sun $L P$, Gong $Y H$, Wang $L$, Yuan $Y$ : Serum pepsinogen levels and their influencing factors: a population-based study in 6990 Chinese from North China. World J Gastroenterol 2007, 13(48):6562-6567.

15. Shiraki M, Yamazaki Y, Kuroda T, Tanaka S, Miyata K: Serum level of pepsinogen significantly associated with gastric distress induced by amino-bisphosphonates. Osteoporos Int 2011, 22(6):1717-1723.

16. Kiyohira K, Yoshihara M, Ito M, Haruma K, Tanaka S, Chayama K: Serum pepsinogen concentration as a marker of Helicobacter pyloriinfection and the histologic grade of gastritis; evaluation of gastric mucosa by serum pepsinogen levels. J Gastroenterol 2003, 38(4):332-338.

17. Correa P: Human gastric carcinogenesis: a multistep and multifactorial process-first American cancer society award lecture on cancer epidemiology and prevention. Cancer Res 1992, 52(24):6735-6740.

18. Lorente S, Doiz O, Trinidad Serrano M, Castillo J, Lanas A: Helicobacter pylori stimulates pepsinogen secretion from isolated human peptic cells. Gut 2002, 50(1):13-18

19. Derakhshan MH, Malekzadeh R, Watabe H, Yazdanbod A, Fyfe V, Kazemi A, Rakhshani N, Didevar R, Sotoudeh M, Zolfeghari AA, et al: Combination of gastric atrophy, reflux symptoms and histological subtype indicates two distinct aetiologies of gastric cardia cancer. Gut 2008, 57(3):298-305.

20. Waalewijn RA, Meuwissen SG, Pals G, Hoefsmit EC: Localization of pepsinogen ( $A$ and $C$ ) and cellular differentiation of pepsinogen-synthesizing cells in the human gastric mucosa. Eur J Cell Biol 1991, 54(1):55-60.

21. Stemmermann GN, Samloff IM, Hayashi T: Pepsinogens I and II in carcinoma of the stomach: an immunohistochemical study. Applied pathology 1985, 3(3):159-163.

22. Aydemir S, Borazan A, Acikgoz S, Ustundag Y, Yilmaz A: The effects of continuous ambulatory peritoneal dialysis and hemodialysis on serum pepsinogen concentrations in patients with chronic renal failure. Tohoku J Exp Med 2005, 205(3):263-268.

\section{doi:10.1186/1472-6890-13-22}

Cite this article as: Li et al:: Pepsinogen I and II expressions in situ and their correlations with serum pesignogen levels in gastric cancer and its precancerous disease. BMC Clinical Pathology 2013 13:22. 